\title{
Post-Stroke Rehabilitation Exosceleton Movement Control using EMG Signal
}

\author{
Akif Rahmatillah", Osmalina Nur Rahma*, Muhammad Amin", Septian Indra Wicaksana ${ }^{\#}$, \\ Khusnul Ain ${ }^{\#}$ and Riries Rulaningtyas ${ }^{\#}$ \\ \#Biomedical Engineering Study Program, Departmen of Physics, Universitas Airlangga, Jl. Mulyorejo, Surabaya, 60115, Indonesia \\ E-mail: riries-r@fst.unair.ac.id
}

\begin{abstract}
Post-stroke rehabilitation device is very important nowadays, considering the high rate of disability caused by stroke especially arm function. About $50 \%$ of stroke survivors experience the unilateral motor deficits which decreased upper extremity function. Therefore, hand and shoulders therapy are generally performed in advance to support patients' daily activities. Electromyograph (EMG) signals from selective muscles were proven to provide additional power for post-stroke rehabilitation device to recover more quickly because the patient participates actively in rehabilitation. This paper describes a preliminary prototype of upper limb exoskeleton for post-stroke therapy devices utilizes automatic control algorithm to control human arm movement with one degree of freedom based on a myoelectric signal of muscle biceps brachii from their unaffected side. This study used low-cost instruments and digital signal processing, such as IIR low pass filter followed by Kalman filter to generate the myoelectric signal that separated from noise as an input for controlling the DC motor which moved the exoskeleton of arm therapy mechanic. The accuracy of system performance in this study was $95 \%$. Hopefully, this device can help stroke survivors to perform therapy independently without depending on therapists so that rehabilitation will be more effective and efficient.
\end{abstract}

Keywords - Post-stroke rehabilitation; EMG; Exoskeleton; IIR Filter; Kalman Filter

\section{INTRODUCTION}

The declining quality of life in this modernization era tend to increase the risk of disease. Unhealthy lifestyle and the unbalanced diet are the main factors of cardiac disease and stroke, which are the leading cause of death in almost all hospital in Indonesia, around 15,4\%. The Ministry of Health stated that the prevalence of Stroke sufferers is predicted to increase to 25-30 per mile with the rate of stroke disability reached $65 \%$ [1]. Therefore, post-stroke rehabilitation is needed considering the high level of disability caused by stroke. Post-stroke rehabilitation helps stroke survivors restore the lost or the weakened body function due to damage in part of the brain caused by stroke. About $50 \%$ of stroke survivors experience the unilateral motor deficits [2] which decreased upper extremity function. Thus, rehabilitation is generally performed on hand and shoulder movements in advance to support patients' daily activities.

Recently, Electromyography (EMG) is widely used to aid post-stroke rehabilitation because it is believed that active rehabilitation requiring patient participation can provide more effective and efficient outcomes. The EMG signal is a bioelectric signal that records the electrical activity of the muscle. EMG signals along with the automatic control device can help overcome the deficiencies in rehabilitation that are generally performed in hospitals. Generally, rehabilitation is done based on the direction of the therapist so that the patient will rely heavily on the therapist which leads to longer recovery time if the patient is passively practicing. However, post-stroke therapy devices based on the myoelectric signal which utilizes myoelectric control as control algorithm can help stimulate the muscles in the body of the stroke patient to recover more quickly because the patient participates actively in rehabilitation.

Previously, many studies have applied EMG signals to continuously control the exoskeleton robots that can be worn by the human subject as an assistive device for post-stroke rehabilitation. EMG signals from selective muscles were used to estimate the joint torque and applied the assistive torque to the joint to provide additional power for myoelectric devices. Rong Song, et.al [3] investigated the myoelectric controlled of robotic system's effect on the combination of assistive and resistive torque to assist elbow training for post-stroke people. The result showed that the upper limb functions were improved.

This paper describes a preliminary prototype of upper limb exoskeleton for post-stroke therapy devices utilizes automatic control algorithm to control human arm movement with one degree of freedom based on a 


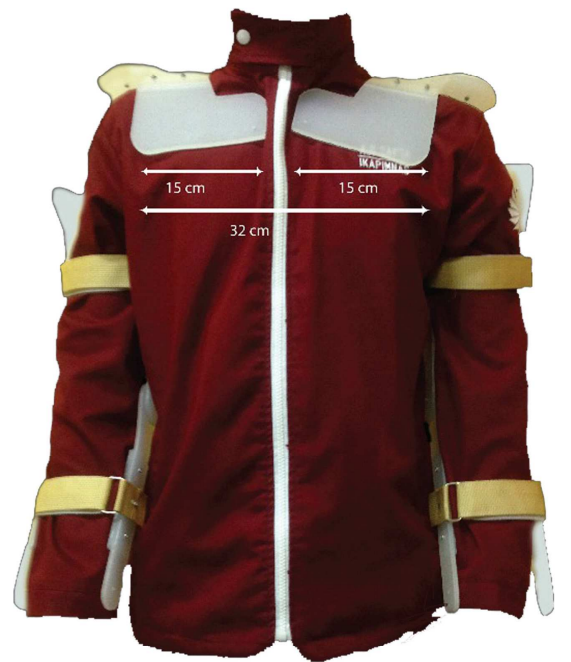

(a)

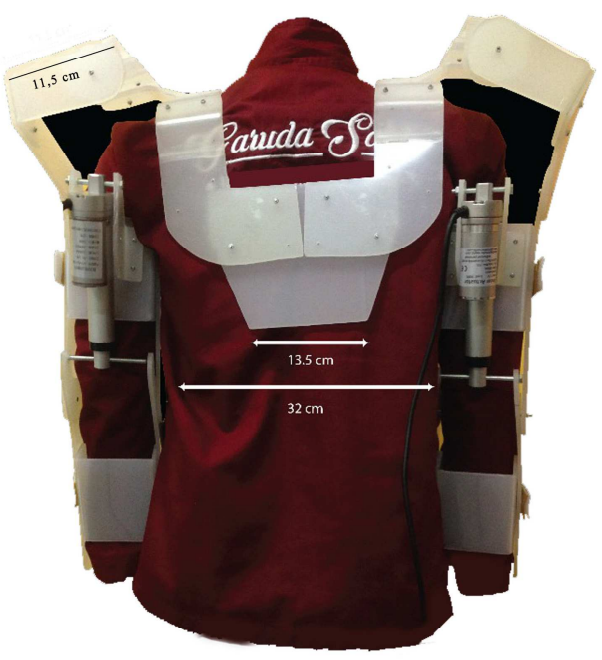

(b)

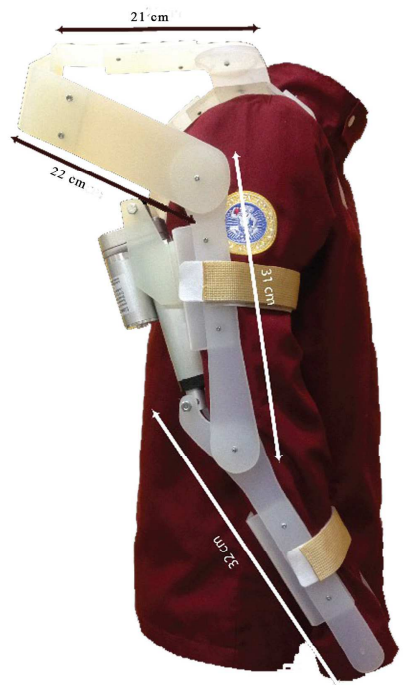

(c)

Fig. 1 The Exoskeleton of post-stroke rehabilitation device (a) front (b) back (c) lef/right

myoelectric signal of muscle biceps brachii from their unaffected side. Stroke survivors can use their unaffected arm to control their affected side for theraphy and this strategy could give a significant improvement in their muscle [3]-[5]. Therefore, processing the myoelectric signal that separated from noise generated during EMG recording became important in developing the rehabilitation devices based on myoelectric control. In this prototypye, some filters were added in signal processing to reduce noise, such as the IIR (Infinite Impulse Response) low pass filters and Kalman filter for smoothing the signals at low frequency thus provide better control to controll the movement of the poststroke rehabilitation device. It is expected that this device can help stroke survivors to perform therapy independently without depending on therapists thus rehabilitation will be more effective and efficient.

\section{MATERIAL \& METHODS}

\section{A. Experiment Protocol}

Four healthy male subject participated in this study; The subject had no neuromuscular injury and was asked to stand upright, with their heads, eyes, and toes facing forward. Both hands are placed on the side of the body with open palms forward. Three surfaces EMG (s-EMG) electrode were used to record myoelectric signals; two electrodes placed on the biceps brachii muscle and one electrode as a common ground, at the elbow. As shown in Fig. 1 the subject wore an exoskeleton which made from acrylic with a DC motor on the elbow joint.

The exoskeleton design in Fig. 1 can be used on both right and left arm but in this study, its used only in one side. The subject wore the device on the left arm and the EMG signal was recorded from the right arm as an input for myoelectric control that commands the DC motor to move at an angle of $0^{\circ}$ to $120^{\circ}$. The subject was asked to move the right elbow in flexion and extension which represent contraction and relaxation 10 times, respectively. Every consecutive move was separated with 5-second rest, while the different task was separated with 1-minute rest.

\section{B. Prototype System}

The diagram of post-stroke rehabilitation system is shown in Fig. 2, which is consist of data acquisition from surface electrode using Olimex Shield EKG/EMG (OLIMEX Ltd, Plovdiv, Bulgaria) along with Arduino Uno as a microcontroller. Olimex Shield and Arduino were chosen as an instrument hardware because these can acquire a good myoelectric signal, besides that both are a low-cost instrument which has good performance as commercially available electromyography [6]. Myoelectric signals then were processed using IIR low pass filter and Kalman filter to achieve smooth signal that separated from noise as an input for controlling a DC motor. The DC motor will move to angle $0^{\circ}$ and $120^{\circ}$ according to the myoelectric signal of flexion and extension biceps muscles.

The architecture of Olimex Shield EKG/EMG is explained further in Fig. 3. The Shiled EKG/EMG board consist of high voltage protection followed by high frequency (HF) rejection. Total gain that provided by Olimax Shield is a product of each discretization stage: instrumental amplifier $(\mathrm{G}=10)$, OAmp with regulated gain $(\mathrm{G}=5.76 \ldots 101)$ and $3^{\text {rd }}$ order Besselworth filter $(\mathrm{G}=3.56)$

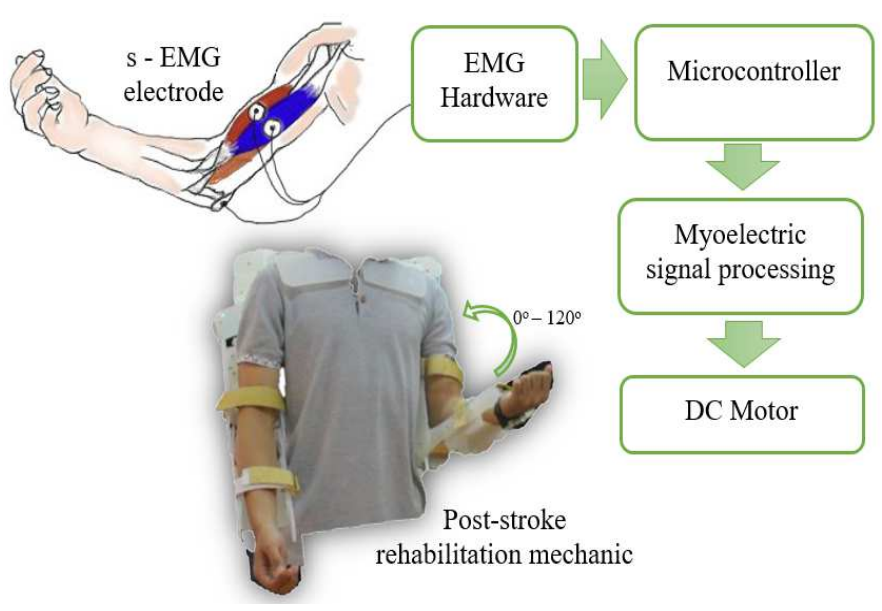

Fig. 2 Diagram of post-stroke rehabilitation system 


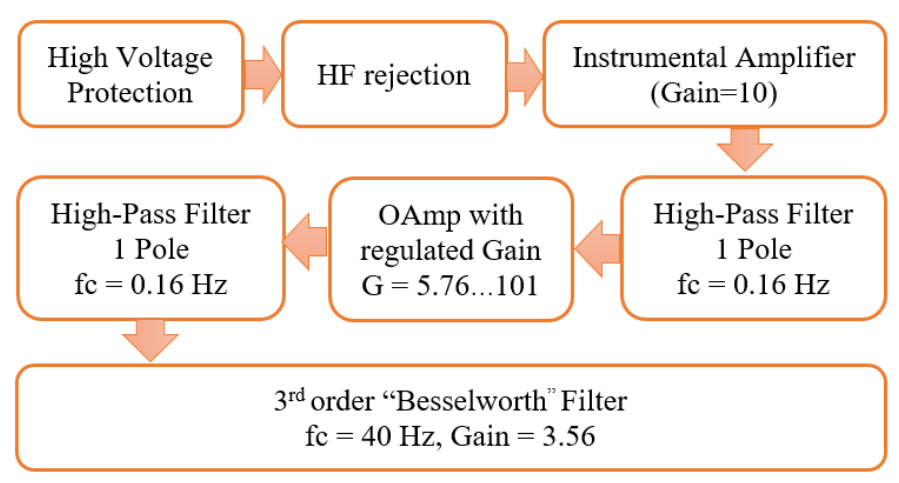

Fig. 3 EMG shield hardware

with cut-off frequency $40 \mathrm{~Hz}$. Olimex Shield also provide two stage of high pass single pole filter with cut-off frequency $0.16 \mathrm{~Hz}$. The Olimex Shied EKG/EMG have used 10-bit ADC with $256 \mathrm{~Hz}$ sampling rate [7].

IIR filter that used in this study was single pole (RC type) low pass filter which is used for smoothing an analog input, while the Kalman filter are explained futher in the following section.

\section{Kalman Filter}

The Kalman filter is a set of mathematical equations which originally is functioned as an estimator. Kalman filter provides an efficient computational that minimize the mean squares error. Since Kalman filter can estimate the next state of the signal based on the previous signal including its noisy, then it is considered as a powerful adaptive filter which solves the problem of the Wiener work in a matter of filtering the additive noise in the signal [8]-[10].

Kalman filter is a practical solution to control a dynamic system where it is not always possible to measure every variable that wanted to control, and the Kalman filter provides a means for inferring the missing information from indirect (and noisy) measurements [9]. In performing an estimation of the next state, Kalman filter uses some parameters, such as a process noise $\mathrm{Q}$ and a measurement noise R. These need to be initialized with a certain value to overcome a good estimation of the signal. Thus, made the determination of noise parameters values $(\mathrm{Q}$ and $\mathrm{R})$ became important to get a good performance.

In this study, Kalman filter used to separate a myoelectric signal from noise during recording and smooth the low frequency, which can result in good performance for controlling the DC motor of post-stroke rehabilitation device based on EMG signal of contraction and relaxation.

The two equation of Kalman Filter is shown in equation (1) and (2), where $x_{k}$ is the result of Kalman filter estimation in $k$-th state from a linear addition of the previous estimation $x_{k-1}$ and a control input $u_{k}$ along with the process noise $\boldsymbol{w}_{k}$. Matrices $A, B$, and $H$ which will be numerical constants and even most probably, these will be equal to 1 are used to relate the parameters. Matrix $A$ relates the current $x_{k}$ and the previous estimation $x_{k-1}$. Matrix $B$ relates the current estimation $x_{k}$ and the control input $u_{k}$, while matrix $H$ relates the input measurement $z_{\mathrm{k}}$ with the current estimation $x_{k}$ and the measurement noise $v_{k}$.

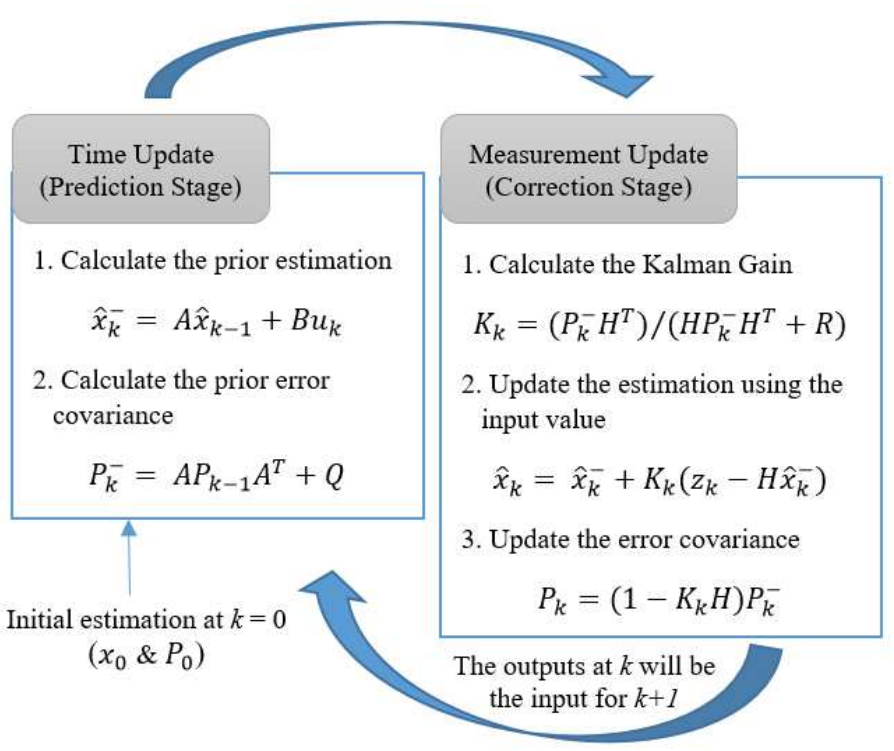

Fig. 4 The iteration process

$$
\begin{gathered}
x_{k}=A x_{k-1}+B u_{k}+w_{k-1} \\
z_{k}=H x_{k}+v_{k}
\end{gathered}
$$

Kalman Filter implementation is divided into the following steps:

Step 1: Prediction and correction process.

In this step, there are two different set of equation: time update (prediction) and measurement update (correction). The equation of the time update process is written in Eq. 3 and Eq.4.

$$
\begin{aligned}
& \hat{x}_{k}^{-}=A \hat{x}_{k-1}+B u_{k} \\
& P_{k}^{-}=A P_{k-1} A^{T}+Q
\end{aligned}
$$

A time update process (correction) consist of prior estimation $\widehat{x}_{k-1}$ and a prior error covariance $\boldsymbol{P}_{k-1}$. $\hat{\boldsymbol{x}}_{k}^{-}$is a temporary estimation before the measurement update (correction), while temporary error covariance $p_{k}^{-}$is a linear addition of the prior error covariance $P_{k-1}$ and a process noise Q.

A measurement update consist of calculating a Kalman gain $K_{k}$, an update estimation $\hat{x}_{k}$ and an update error covariance $P_{k}$ which are written in the following equation.

$$
\begin{gathered}
K_{k}=\left(P_{k}^{-} H^{T}\right) /\left(H P_{k}^{-} H^{T}+R\right) \\
\widehat{x}_{k}=\widehat{x}_{k}^{-}+K_{k}\left(z_{k}-H \widehat{x}_{k}^{-}\right) \\
P_{k}=\left(1-K_{k} H\right) P_{k}^{-}
\end{gathered}
$$

Step 2: Iteration process.

In the iteration step, the previous estimated and previous error covariance will be an input for the prediction stage. The iteration process is described in Fig. 4. 


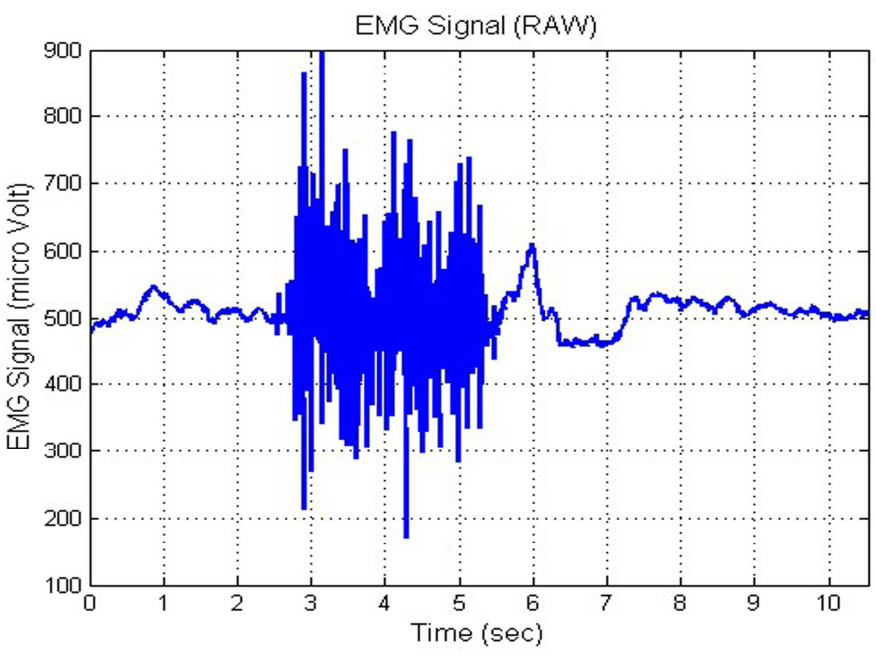

(a)

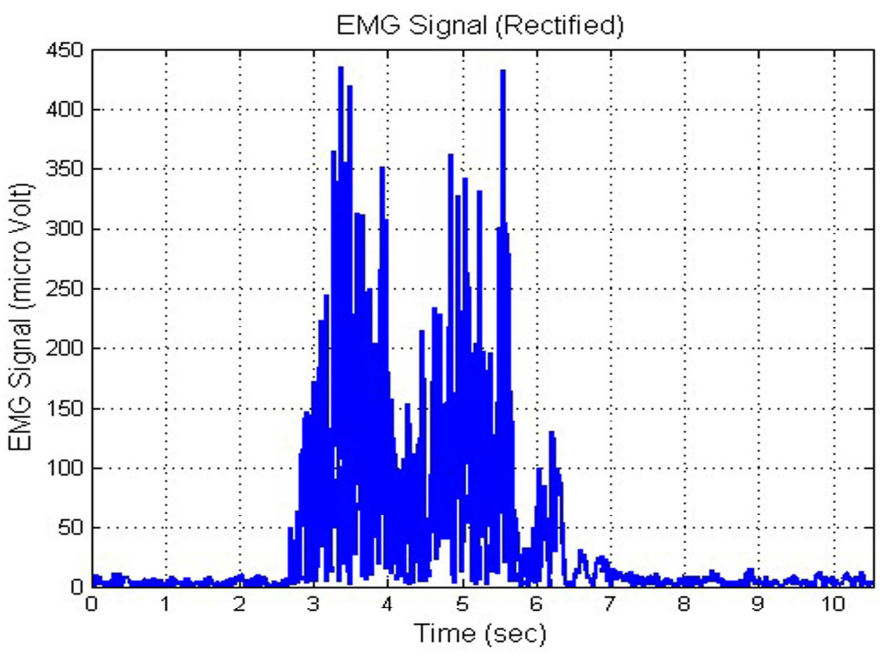

(c)

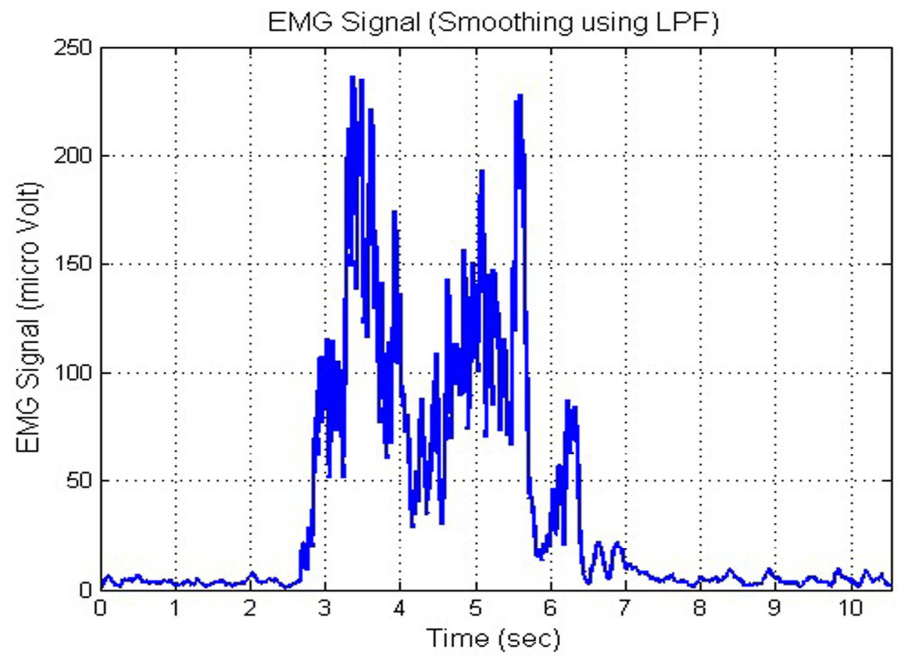

(b)

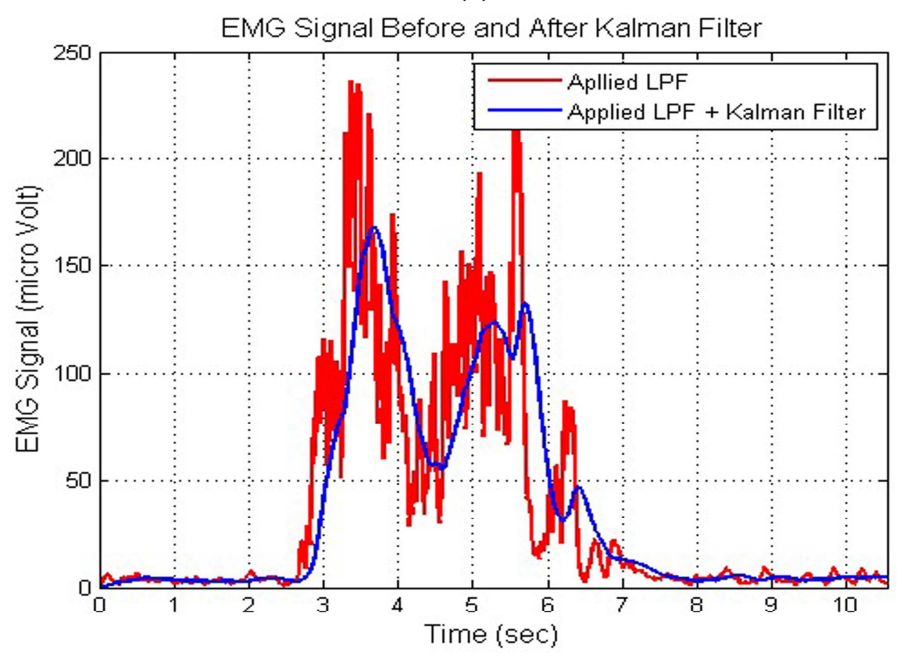

(d)

Fig. 5 The result of signal processing

\section{RESULT AND DISCUSSION}

The aim of this study was to achieve the value for thresholding the myoelectric signal in order to distinguish

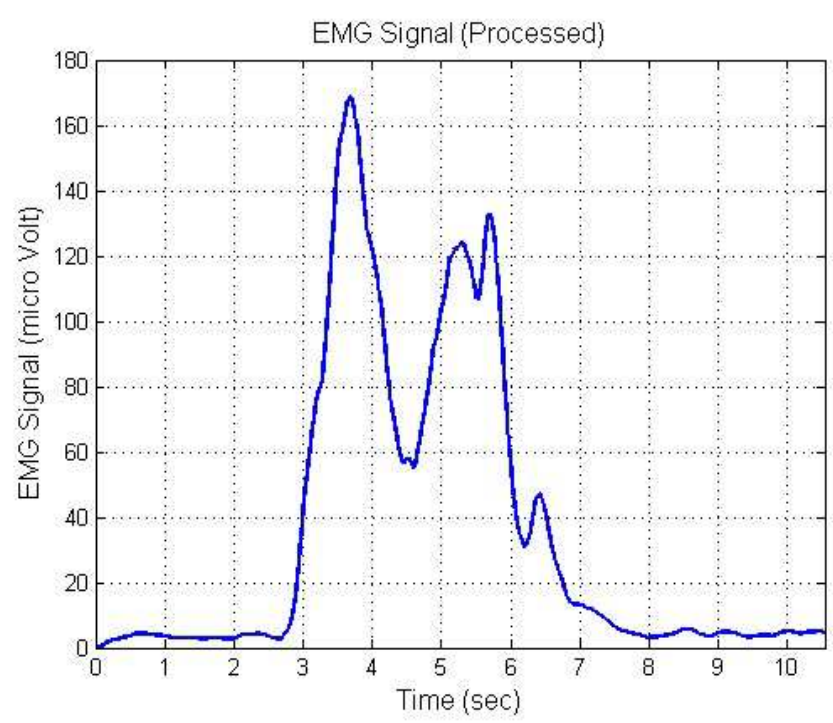

Fig. 6 EMG Signal after processed with Kalman Filter the DC motor control for flexion and extension movement. Simply, the thresholding was like an on-off for the system. Therefore, the signal processing to get the best value for thresholding played an important role.

The signal processing was begun by collecting a raw EMG signal from EMG hardware using Olimex Shield EKG/EMG, which is shown in Fig. 5 (a). This signal then was rectified (Fig. 5 (b)) in order to get the positive value of EMG signal by lowering the baseline to zero and absolutizing the negative value. This was needed since the value of contraction signal was varied from positive to negative. Fig. 5 (b) shows the existence of ripples while the expected values were supposed to be increased when the subject did the contraction (flexion movement) and decrease when the subject di the relaxation (extension movement), until finally zero. Thus, the following step was filtering the ripples that generated during the recording using the IIR single pole low pass filter. The result of low pass filter is shown in Fig. 5 (c). However, the signal was still looked rough because of the limited library provided by Arduino, which was only able to design single pole IIR filter order 1. This resulted in a wide transition band from passband to stopband. To overcome this shortcoming, Kalman filter was added (Fig. 5 (d)) in order to smooth the signal after passing 


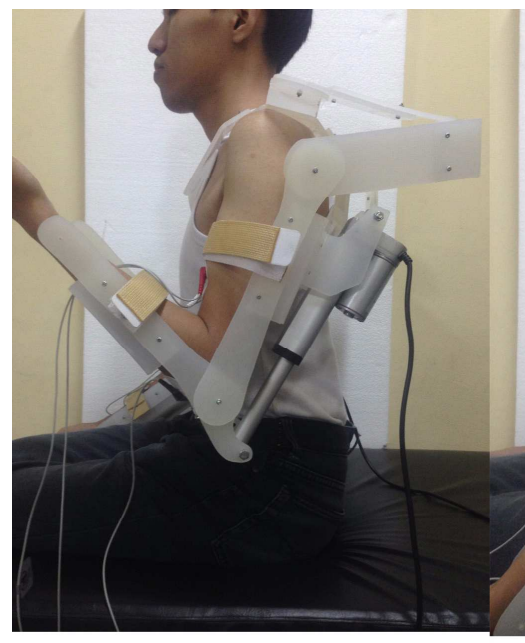

(a)

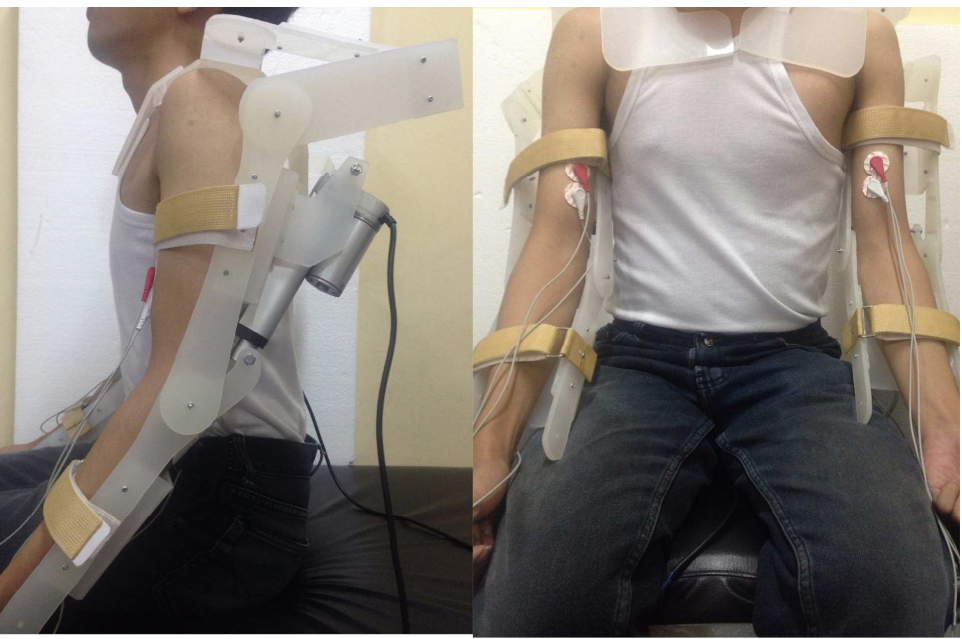

(b) (c)

Fig. 7. System tested on subject (a) flexion (b) extension from side (c) extension form front

TABLE I.

THE SYSTEM PERFORMANCE OF PROTOTYPE

\begin{tabular}{|c|c|c|c|c|c|c|}
\hline Subject & Side of Arm & Succeeded & Failed & $\begin{array}{l}\text { Succeeded } \\
\text { percentage }\end{array}$ & $\begin{array}{c}\text { Flexion Time } \\
\text { Average (s) }\end{array}$ & $\begin{array}{c}\text { Extension Time } \\
\text { Average (s) }\end{array}$ \\
\hline \multirow{2}{*}{1} & Right & 10 & 0 & $100 \%$ & 6.99 & 6.39 \\
\hline & Left & 8 & 2 & $80 \%$ & 7.24 & 6.32 \\
\hline \multirow{2}{*}{2} & Right & 10 & 0 & $100 \%$ & 6.89 & 6.4 \\
\hline & Left & 10 & 0 & $100 \%$ & 6.9 & 6.35 \\
\hline \multirow{2}{*}{3} & Right & 9 & 1 & $90 \%$ & 7.12 & 6.39 \\
\hline & Left & 9 & 1 & $90 \%$ & 6.99 & 6.32 \\
\hline \multirow{2}{*}{4} & Right & 10 & 0 & $100 \%$ & 6.96 & 6.48 \\
\hline & Left & 10 & 0 & $100 \%$ & 6.95 & 6.33 \\
\hline \multicolumn{4}{|c|}{ Average } & $95 \%$ & 7.005 & 6.3725 \\
\hline
\end{tabular}

the IIR low pass filter with the assumption of noise covariance value $\mathrm{Q}=0.5$ and $\mathrm{R}=0.5$.

The outcome signal after processing the Kalman filter is shown in Fig. 6. Based on this result, the algorithm for controlling the DC motor of post-stroke rehabilitation is witten in the Algorithm 1.

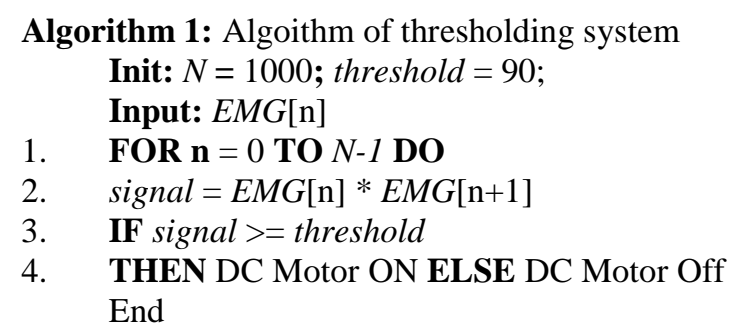

The system was tested on four healthy male subjects (Fig. 7) with 10 times repetition for flexion and extension movement, respectively and it obtained a great result. Both of the flexion and extension movement acquired $95 \%$ accuracy even though there were still few second delays that occurred between the time of the muscle moved and the DC motor started to operate. The average time to move the exoskeleton from contraction (movement flexion) to relaxation (movement shift) needed about 13 seconds. The system performances are summarized in Table 1.

Table 1 shown that DC motor needed at least 6 seconds to moved the exoskeleton. The fast speed can be dangerous to the patients if they still in the early period of therapy because patient's muscle is still stiff so the movement so this was considered to be fit to control the speeds for therapy.

\section{CONCLUSIONS}

This study showed that Kalman filter was proven to have good performance as a filter as well as an estimator, especially for a bioelectric signal. IIR low pass filter followed by Kalman filter could obtain the performance of system test accuracy was $95 \%$. This study used 0.6 as the value of the noise parameters ( $\mathrm{Q}$ and $\mathrm{R})$. Moreover, a lowcost instrument such as Olimex Shield EKG/EMG along with Arduino can be developed as an arm therapy device for stroke survivors to aid the active rehabilitation. Hopefully, this device can give a low-cost therapy yet effective and efficient.

\section{ACKNOWLEDGMENT}

This study was supported by The Ministry of Research, Technology and Higher Education of the Republic Indonesia (004/SP2H/PPM/DRPM/V/2017) and Airlangga University. We would like to thank dr. I Putu Alit Pawana, Sp. KFR (Physiatrist) for help in this study.

\section{REFERENCES}

[1] Ministry of Health, "Presiden Resmikan RS Pusat Otak Nasional," 2014. [Online]. Available: 
http://www.depkes.go.id/article/view/201407200001/presidenresmikan-rs-pusat-otak-nasional.html. [Accessed: 21-Feb-2018].

[2] J. A. Franck, "Concise Arm and Hand Rehabilitation Approach in Stroke," vol. 3, no. 4, 2015.

[3] R. Song, K. Tong, X. Hu, and L. Li, "Assistive Control System Using Continuous Myoelectric Signal in Robot-Aided Arm Training for Patients After Stroke," IEEE Trans. Neural Syst. Rehabil. Eng. (Volume16, Issue 4 ), vol. 16, no. 4, pp. 371-379, 2008.

[4] W. H. Chang and Y.-H. Kim, "Robot-assisted Therapy in Stroke Rehabilitation," J. Stroke, vol. 15, no. 3, p. 174, 2013.

[5] C. G. Burgar, P. S. Lum, P. C. Shor, and H. F. Machiel Van der Loos, "Development of robots for rehabilitation therapy: the Palo Alto VA/Stanford experience.," J. Rehabil. Res. Dev., vol. 37, no. 6, pp. 663-73, 2000.

[6] M. Reinvee, P. Vaas, J. Ereline, and M. Pääsuke, "Applicability of Affordable sEMG in Ergonomics Practice," Procedia Manuf., vol. 3, no. Ahfe, pp. 4260-4265, 2015.
[7] Olimex, "Sheild EKG-EMG - Open Source Hardware Board," no. June, 2015.

[8] T. Triwiyanto, O. Wahyunggoro, H. A. Nugroho, and H. Herianto, "Evaluating the performance of Kalman filter on elbow joint angle prediction based on electromyography," Int. J. Precis. Eng. Manuf., vol. 18, no. 12, pp. 1739-1748, 2017.

[9] M. Grewal and A. Andrews, Kalman filtering: theory and practice using MATLAB, vol. 5. 2011.

[10] M. N. Mohd Nor,R. Jailani,N. M. Tahir,Ihsan Mohd Yassin,Zairi Ismael Rizman and Rahmat Hidayat,"EMG Signals Analysis of BF and RF Muscles In Autism Spectrum Disorder (ASD) During Walking," International Journal on Advanced Science, Engineering and Information Technology, vol. 6, no. 5, pp. 793-798, 2016. [Online]. Available: http://dx.doi.org/10.18517/ijaseit.6.5.1205.

[11] G. Welch and G. Bishop, "An Introduction to the Kalman Filter," In Pract., vol. 7, no. 1, pp. 1-16, 2006. 